\title{
Into the Online Space: Outcomes for a PASS Online Pilot Across Different First Year University Subjects
}

Tracey Woolrych ${ }^{*}, 1$, Melissa Zaccagnini², Moira Stephens ${ }^{3}$, Murray Stace $^{4}$, Rebekkha Middleton $^{3}$, Melissa Bergner $^{2}$, Sian O’’sullivan $^{5}$, Reetu Verma ${ }^{6}$

${ }^{1}$ University of Wollongong; School of Psychology; UOW, 2522, Australia

${ }^{2}$ University of Wollongong; PASS; UOW, 2522, Australia

${ }^{3}$ University of Wollongong; School of Nursing; UOW, 2522, Australia

${ }^{4}$ University of Wollongong; LTC; UOW, 2522, Australia

${ }^{5}$ University of Wollongong; Peer Learning; UOW, 2522, Australia

${ }^{6}$ University of Wollongong; School of Accounting, Economics \& Finance; UOW, 2522, Australia

\begin{tabular}{l} 
A R T I C L E I N F O \\
\hline Article history: \\
Received: 30 September, 2019 \\
Accepted: 24 December, 2019 \\
Online: 22 January, 2020
\end{tabular}

Keywords:

Peer Assisted Study Sessions

Online Learning

First year University students

\begin{abstract}
A B S T R A C T
Peer Assisted Study Sessions (PASS) is a student let program designed to support students transitioning into university and tackling traditionally difficult first year core subjects. The model is collaborative with student leaders facilitating activities and discussions driven by student need. Consistently research has found that students can benefit, in terms of increased grades, from attending PASS, however findings for online delivery modes are mixed. These studies have generally only compared face to face (F2F) with online modes of PASS-like programs for one subject. No study has compared different subjects from varying disciplines to investigate if the benefits of PASS online are the same for all students. PASS at UOW conducted a pilot study of synchronous online sessions, tested across three different first year university subjects. A total of 1.471 students enrolled into these subjects, with 409 attending some form of PASS. Result revealed PASS students gained significantly higher average final marks compared to students who did not attend any type of PASS, regardless off subject. However, results for PASS varied depending upon mode of delivery engaged in ( $F 2 F$ or online) and also with subject. Although not all differences were statistically significant, trends suggest a student/subject interaction that may vary the amount of benefit gained from PASS online formats. Possible drivers for these results are discussed as well as consideration given to cohort effects and student skills for online learning modes.
\end{abstract}

\section{Introduction}

As Universities strive to meet the needs of more diverse student populations, online learning options are being rolled out Australia wide. Time poor students, many of whom have families and/or work commitments, require more flexibility to complete their degrees, including a need for online-based supports [1-2]. Peer led learning assistance programs are following this trend by offering synchronous online learning sessions [3]. However it is unclear if students are benefitting from this mode of learning, especially in

"Corresponding author: Tracey Woolrych, Email: woolrych@uow.edu.au the first year space where students may not yet be fully independent learners [4]. Currently research into online versions of PASS-like programs have offered positive results in terms of benefits for students. However, many of these studies investigate only one subject at a time, making it unclear whether student and/or subject characteristics may influence the benefits students can obtain.

Research on PASS-like programs has shown many benefits for students including increased grades, particularly in face to face (F2F) delivery modes [5-6]. These findings seem consistent across a range of different courses [7]. However, findings reveal this 


\section{T. Woolrych et al. / Advances in Science, Technology and Engineering Systems Journal Vol. 5, No. 1, 142-150 (2020)}

consistency is not present for online versions of PASS [8-11]. The F2F environment comes with a range of stimuli and cues which are important in facilitating learning [8]. Given the collaborative nature of Peer Assisted Study Sessions (PASS), these cues become essential for successful student/student and student/leader interactions. There is no guarantee that these can be created or recreated in the online space. Online learning modes may not be able to emulate the F2F student experience [4, 12-14]. One could argue that they should not try, given that the content and mode of delivery for different subjects are intrinsically linked. It is this that may impact on the success of online delivery. Not every subject may be suitable to an online format, with important learning-based elements lost in an online delivery. Therefore it is vital that research address the question of subject and/or student suitability for online delivery, and whether it is beneficial for student learning.

Although current peer-assisted models span a variety of discipline areas, including Engineering and IT [15], languages [8], and occupational therapy [16] few studies have compared these outcomes across multiple subjects and/or disciplines. Subjects vary in their learning outcomes, and the approaches and skill development requirements to meet these. Therefore, a one-size-fits all approach to the adaptation of F2F peer-led learning programs to online versions may not be advisable. Research comparing peer-led online formats across a range of subjects is required to unpack some of the underlying factors that may be contingent on student success. This paper seeks to address this gap by comparing different first year subjects across multiple disciplines. This allows us to explore whether PASS online formats are equally beneficial to students in different subjects and whether other factors such as student and/or subject characteristics may play a role. This is essential to the future development of online formats of PASS-like programs.

\section{Peer Assisted Learning (PAL) Programs}

Peer Assisted Study Sessions (PASS) was originally based on supplemental instruction (SI) developed by Dr D Martin at the University of Missouri over 30 years ago [17]. SI programs have since spread around the world with many tertiary institutions adopting them in an effort to support their students. PASS have been operating in collaboration with Australian Universities for many years. According to the Supplemental Instruction Journal (2016), SIs are informal sessions whose direction is driven by students and led by students (Leaders) who have previously done well in the subject. Modelled on SI, PASS leaders do not 'teach' as much as facilitate activities and discussions designed to help students more clearly and deeply understand the subject content [17-18]. Students also develop and practice effective study skills [19]. Collaboration is key here, a far cry from the stand and deliver techniques of many lectures: at PASS you will find leaders helping students, and students helping students [20-21].

Research into the peer-led learning space reveals many benefits for students. On average, students who attend these programs obtain higher final marks compared to those that do not attend [56]. A higher number of students pass the subject linked with PASS, and more students finally graduate [7]. Dancer et al., [22] also found that there were higher retention rates and few withdrawals in these subjects. Lower-achieving students gained more benefits in terms of grade increases compared to higherachieving students [22]. The positive benefits that students can gain from PASS-like programs are clear. What is less clear is how these peer-led models of learning translate into the online space.

\subsection{Findings in the online space}

Increasingly today's students are facing time pressures, trying to balance work/family and study commitments. This results in students desiring more flexible study options at University. Education providers are meeting this need through the delivery of blended and online learning [23]. Online study is offered over a wide range of subjects and courses. Peer led assisted programs are following suit, offering online, mostly synchronous, study sessions for students.

Research into the benefits and success of peer lead online learning is still growing, and the literature is not of a single voice in its success. Some studies have found student benefits in the form of increased satisfaction and higher average grades e.g.:[2428]. Students also report reduced feelings of isolation [26], enjoying the flexibility [20] and collaboration [5, 29-30] that resulted from the online sessions. Online formats of peer lead learning resulted in increased student interest and engagement [30], as well as increased understanding [29]. In particular, those subjects that required skills development in IT [15] and languages $[8,31]$ reported success in the online mode.

Some studies revealed no differences in average final marks between students attending F2F peer-led learning sessions, compared to online attendance $[8,26-28]$ suggesting, on the surface, that both modes afford students the same benefits. However other studies have found a lack of grade increases for their online cohorts [6]. These variations in results could be explained by poor student uptake for the online formats $[13,23$, 32] and a lack of student participation in feedback [33]. Technical issues experienced in the online format may also result in less that optimal learning environments resulting in some students abandoning the sessions altogether [32]. Recent studies have also highlighted the need for leader training specifically for the online mode of delivery $[13,23,32]$. Terminology is also an issue in this area of research. The definitions of PASS attendance are variable which may explain some of these results. As Dawson et al., [7] point out, the distinction between peer-groups and non-peer groups is at times arbitrary with studies using cut-offs varying from 1, 3 or more classes to define group conditions. The variation and rapidly evolving nature of the technology being used may also contribute to variable findings, with online studies needing to be read in the broader context of the technology "point in time".

The lack of gains achieved in online learning formats may also be the result of insufficient student skills. These studies often involve first year university students, some of whom struggle with the self-reliant and self-driven nature of online formats [4]. They may not yet have development the necessary problem solving [34], time-management and self-management skills [35, also see 3], such as motivation and commitment, necessary to succeed [36-38]. The online learning format presents a large departure from traditional learning environments many students would have been exposed to in their prior learning. Mature age students, on the other hand, may lack the necessary digital literacy and confidence to successfully navigate the online learning environment [39-42]. 


\section{T. Woolrych et al. / Advances in Science, Technology and Engineering Systems Journal Vol. 5, No. 1, 142-150 (2020)}

Studies on blended learning models report push-back from some students against taking responsibility for their own learning [14, 43]. Students new to university may have had little experience in online learning and so lack the relevant skills required for success.

An alternative explanation may be that the different subjects attract different types of students. Therefore, there may be unseen cohort effects driving some outcomes. Few studies have compared multiple subjects from different disciplines.

Another possible explanation may be that not all subjects are suited to an online mode of delivery. Whilst peer-led learning has been conducted across a range of subjects and disciplines, it should be remembered that subjects vary in their learning outcomes, approaches and requirements, meaning a one-size fits all approach may not be appropriate. The literature is unclear on this, as some studies do not state the subject under investigation, nor the faculty within which the subject is situated. The findings do suggest that STEM (science, technology, engineering, and maths) subjects do well in the online format [7,44], although some studies did not find any grade increases for those cohorts [30, 33]. PASS conducted for Biology, as both a STEM and nursing subject, resulted in higher grades for students who attended in both the F2F and online modes [27-28]. Other subjects that have had successful outcomes in online formats are pre-doctoral (dentist) studies [24], and Education [29]. Dennis' [45] study found no differences in average grades between F2F and online versions of PASS for physical therapy students. Overall the literature suggests that students of most subjects can benefit from PASS-like programs, however whether these benefits successfully translate into the online space is less clear. In order to identify the factors that influence PASS-online success, studies need to investigate differences or similarities in outcomes across different subjects, across various disciplines.

\section{Peer Assisted Study Sessions (PASS) at University of Wollongong (UOW)}

The University of Wollongong (UOW) houses the Australian National Centre for PASS. The PASS program was launched in 2002 and in the intervening years has met with much success [46]. Students report higher grades and increased confidence. Traditionally, PASS is run in parallel with a range of first year subjects to support students with their transition to University study. Attached commonly to challenging first year core subjects, PASS is non-remedial, with PASS leaders guided by student needs and concerns. Currently PASS at UOW facilitates over 40 subjects (some in multiple semesters) across all faculties and onshore campuses.

The study sessions are run by PASS leaders, who have successfully passed the subject themselves. The sessions are driven by the attending students who choose the subject content to be focused on for discussion, clarification, or practice. PASS leaders engage students with a range of learning activities and guide students to develop study strategies. Activities in the F2F sessions can include brainstorming, concept lists, filing in the missing elements of an equation, and diagram labelling. The learning environment is collaborative between students and leaders. Students are encouraged to share their thoughts and knowledge with others, sharing answers and processes, often teaching back to other students. PASS students, in this way, have a direct stake in the teaching process, enhancing their own learning experiences.

\subsection{The current project-PASS Online Pilot.}

At UOW the demand for PASS is high. Large first year student cohorts, as well as time and space availability, limit the number of sessions that can be offered for each subject. Students also voiced a desire for some out-of-hours sessions to accommodate work and/or family commitments. Regional students also needed a way to access PASS in the absences of a suitable leader being available on their campus. In response to this, PASS at UOW trialled an online format using Blackboard Collaborate, an online synchronous platform.

PASS is student led and student focused. The selection of an online platform required careful consideration of this. The aim of the pilot was to emulate, as much as possible, the F2F student experience. It was not the aim of the pilot to replace the usual F2F sessions, but rather supplement them, by giving students more flexibility of access. The online environment needed to align with the core values and practices of PASS.

In the spirit of the student-driven principals that lie at the heart of the PASS model, student leaders were recruited to test different synchronous online platforms, as well as host the online sessions during the pilot. Blackboard collaborate was chosen for its flexibility, ease of use, and ease of access (embedded in Moodle). The platform provides for online synchronous discussion spaces, student/student and leader/student interactions, and exchange of document-based information including power point slides.

PASS leaders tested the capabilities of the system through roleplay, swapping between student and leader roles to gain a deep understanding of the student experience. These experiences were shared with other leaders as part of their training for the online system and formed the basis for written guides for use in future training.

Three large cohort subjects from three different faculties were chosen for the pilot which first ran in second session, 2017. All were first year core subjects and traditionally considered difficult and challenging by students. These included: COMM121 (Statistics for Business, Commerce); NMIH106 (Essentials of Care A, Nursing); and PSYC123 (Research Methods and Statistics, Psychology).

It was predicted that if the online version of PASS provided similar benefits to F2F sessions, then, regardless of mode, PASS students would all obtain higher average marks compared to students who did not attend PASS. It was hypothesised that there would be no statistically significant difference in average mean mark achieved between the different PASS delivery modes. Finally, it was hypothesised that, regardless of PASS mode, the more hours dedicated to PASS the greater the benefits for students in the form of higher final marks.

\section{Subject Overviews}

Two of the piloted subjects were statistics-based. COMM121 and PSYC123 are first year introductory, core, statistics subjects in the schools of Business and Psychology respectively. COMM121 deals with quantitative statistical analysis for data in 


\section{T. Woolrych et al. / Advances in Science, Technology and Engineering Systems Journal Vol. 5, No. 1, 142-150 (2020)}

the business and economics environments. Analyses and concepts include probability; hypothesis testing; correlations; regression; and time series forecasting. Students also develop skills in the use of excel and PHStat2 programs. COMM121 is an applied subject, teaching students how to use statistics to answer questions about business success and business-based weaknesses.

PSYC123 is also a quantitative-based statistics subject designed to help students answer questions about the human condition. A core subject for Psychology and Social Science students in the faculty of Social Science, students learn concepts relating to theoretical distributions; sampling; descriptive and inferential statistical analysis (z-scores; correlation; t-tests; chisquare); hypothesis testing; and methodological considerations, including validity and reliability. Students conduct all analysis and calculations by hand with a strong emphasis on result interpretation.

Essentials of Care A (NMIH106) focuses on the skills essential for successful patient/client interactions, including communication; person-centred care; knowledge (intervention; evidence; and health science); skills practice; and documentation. The subject builds directly upon knowledge and skills gained in first session nursing subjects. Foundational science knowledge is at the core of this subject, how it relates to nursing practice and how it informs patient/client communications with other health care personnel.

\section{Methods}

\subsection{Participants}

A total of 1,471 students were enrolled across the three subjects. Students were deemed PASS participants if they attended at least on session in any mode. Those students who did not obtain a final mark or obtained a final mark of zero (0) were excluded from analysis, leaving a sample size of 1,423. Of these, 409 students attended a form of PASS across the three subjects (see table .1. below).

\subsection{Procedure}

PASS in the online format was run concurrently with F2F sessions and with normal subject delivery in each school, throughout the second teaching session of 2017, and was open to all enrolled students from the three subjects piloted. Students voluntarily signed up by enrolling in F2F or online PASS, or a combination of both. Students were briefed about the online pilot which outlined some of the potential benefits of the program and expected time commitments (for feedback via online survey). Students could attend as many or as few PASS as they wished, in any mode of delivery. During week 6 of session, and again in week 13, students were invited to complete a brief Survey-Monkey questionnaire to gauge their experiences with the online format. All data from the questionnaires, and end of session marks for all students in each subject, were de-identified to protect anonymity. This project had ethics approval from UOW (2017/263).

\subsection{Analysis}

Participants were split into four discrete groups, dependent upon the PASS mode engaged in. These were PASS F2F only (PF2F); PASS online only (PO); PASS F2F and online in combination $(\mathrm{PO}+\mathrm{F} 2 \mathrm{~F})$; and no PASS attendance (NP). Sample numbers in the PASS online formats were very low. Nonparametric tests yielded the same results as parametrics, therefore it is the parametric test results given here. Significant results, then, should be interpreted with caution.

\section{Results}

\subsection{Descriptives}

A total of 409 students attended PASS across all three subjects. Students in PSYC123 $(m=69.71)$ achieved the highest grades overall, followed by NMIH106 $(m=66.53)$ then COMM121 $(m$ $=59.12$ ). These differences were all statistically significant $(F(2,1420)=44.69, p<.001$ Students who attended PASS, in any format, achieved higher average marks compared to those that did not attend. For students who attended PASS, PSYC123 students achieved the highest grades $(m=73.19 ; \mathrm{CI}[71.10 ; 75.28])$, followed by COMM121 students $(m=70.35, \mathrm{CI}[67.00 ; 73.69])$ and NMIH106 ( $m=69.39$, CI[66.96;71.82]) (see table .1. below).

For COMM121, 20\% of students attended only 1 session of PASS, compared to $34 \%$ of students in PSYC123, and $40 \%$ of students in NMIH106.

\subsection{PASS modes}

Students who attended any mode of PASS achieved higher average final marks $(m=71.24)$ compared to students that did not attend $(m=62.35 ; \mathrm{t}(970.462)=-9.069, p<.001 ; \mathrm{CI}[-10.82 ;-6.97]$; see figure 1 below).

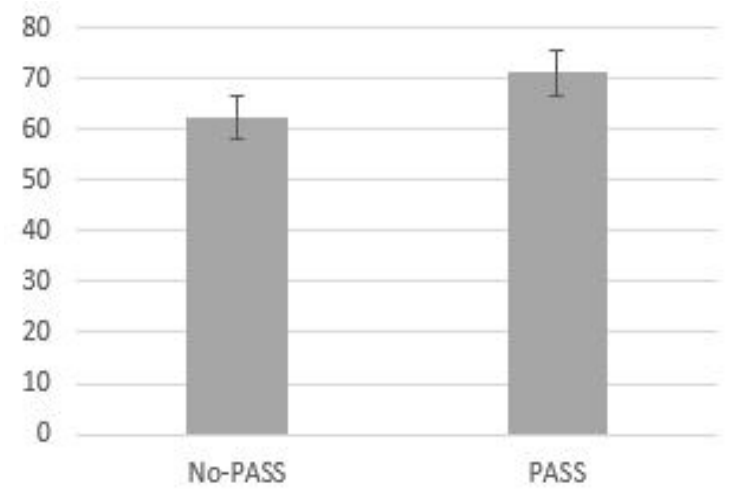

Figure 1: Mean final mark comparisons between No-PASS and PASS groups (regardless of PASS delivery mode).

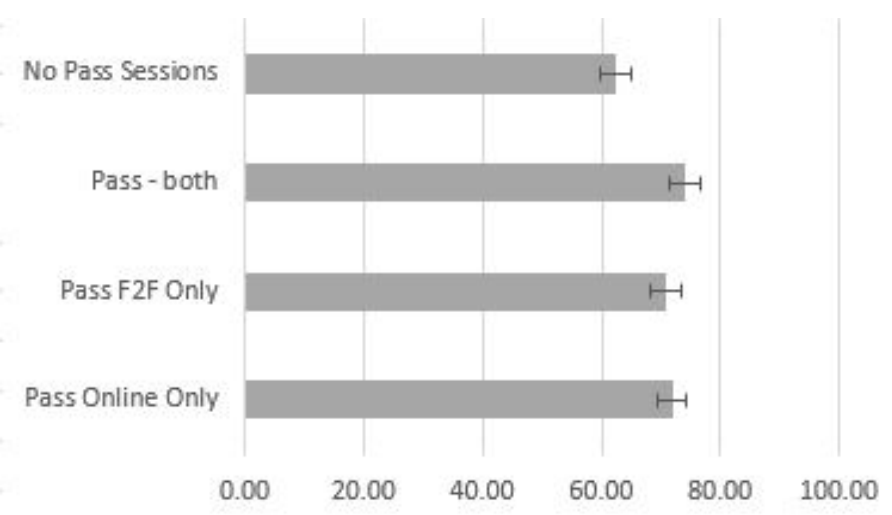

Figure 2: Mean final mark distributions comparing No-PASS and all modes of PASS delivery 
T. Woolrych et al. / Advances in Science, Technology and Engineering Systems Journal Vol. 5, No. 1, 142-150 (2020)

Table 1: Mean final grade and mean hours of PASS attended across all PASS modes, No-Pass and for each subject.

\begin{tabular}{|c|c|c|c|c|c|c|c|c|}
\hline Subject & PASS mode & $\mathbf{n}$ & $\begin{array}{c}\text { Mean Final } \\
\text { Grade }\end{array}$ & SD & CI & $\begin{array}{l}\text { Mean } \\
\text { hours }\end{array}$ & SD & CI \\
\hline \multirow[t]{5}{*}{ COMM121 } & No-PASS & 411 & 55.81 & 23.13 & {$[53.57 ; 58.05]$} & - & - & \\
\hline & $\mathrm{PO}$ & 9 & 67.67 & 7.89 & {$[61.60 ; 73.73]$} & 4.22 & 5.07 & {$[.33 ; 8.12]$} \\
\hline & $\mathrm{F} 2 \mathrm{~F}$ & 97 & 69.78 & 19.59 & {$[65.83 ; 73.73]$} & 5.36 & 3.63 & {$[4.63 ; 6.09]$} \\
\hline & $\mathrm{PO}+\mathrm{F} 2 \mathrm{~F}$ & 15 & 75.60 & 16.09 & {$[66.69 ; 84.51]$} & 9.40 & 4.94 & {$[6.66 ; 12.14]$} \\
\hline & Overall & 532 & 59.12 & 22.98 & {$[57.16 ; 61.07]$} & 5.78 & 4.13 & {$[5.07 ; 6.48]$} \\
\hline \multirow[t]{5}{*}{ NMIH106 } & No-PASS & 258 & 65.21 & 12.55 & {$[63.67 ; 66.75]$} & - & - & \\
\hline & $\mathrm{PO}$ & 9 & 74.22 & 8.15 & {$[67.96 ; 80.49]$} & 1.00 & - & {$[1.00 ; 1.00]$} \\
\hline & $\mathrm{F} 2 \mathrm{~F}$ & 104 & 68.72 & 13.63 & {$[66.07 ; 71.37]$} & 3.60 & 2.68 & {$[3.07 ; 4.12]$} \\
\hline & $\mathrm{PO}+\mathrm{F} 2 \mathrm{~F}$ & 6 & 73.67 & 14.75 & [58.19;89.14] & 5.33 & 2.16 & {$[3.07 ; 7.60]$} \\
\hline & Overall & 377 & 66.53 & 12.95 & {$[65.22 ; 67.84]$} & 3.49 & 2.67 & {$[3.00 ; 3.97]$} \\
\hline \multirow[t]{5}{*}{ PSYC123 } & No-PASS & 345 & 68.00 & 17.80 & {$[66.12 ; 69.89]$} & - & - & \\
\hline & $\mathrm{PO}$ & 15 & 73.00 & 20.23 & {$[61.79 ; 84.20]$} & 4.13 & 3.78 & {$[2.04 ; 6.22]$} \\
\hline & $\mathrm{F} 2 \mathrm{~F}$ & 137 & 73.26 & 12.83 & {$[71.09 ; 75.42]$} & 5.86 & 4.04 & {$[5.18 ; 6.54]$} \\
\hline & $\mathrm{PO}+\mathrm{F} 2 \mathrm{~F}$ & 17 & 72.82 & 15.04 & {$[65.09 ; 80.56]$} & 9.88 & 5.40 & {$[7.11 ; 12.66]$} \\
\hline & Overall & 514 & 69.7082 & 16.74 & {$[68.26 ; 71.16]$} & 5 & 4.36 & {$[5.48 ; 6.74]$} \\
\hline
\end{tabular}

The highest grades were achieved when students attended a combination of PASS online and F2F sessions (see figure 2 below). However, there was no statistically significant difference in grades between the different PASS delivery modes $(F(2,408)=.772, p=.463)$ suggesting that all students benefitted from PASS, regardless of mode.

There were variations between subjects in average final marks for students who attended PASS $(F(2,408)=2.47, p=.086)$, with PSYC123 PASS students obtaining the highest marks (see table 1 above). This difference is close to statistical significance, however, low sample sizes in some of the different PASS modes may underpower this result.

\subsection{PASS modes by subject}

For COMM121, PSYC123 and NMIH106 there were no statistically significant differences in average student marks across the different PASS modes. Trends indicated that, dependent upon the subject taken, the amount of mark increase varied dependent upon the mode of PASS undertaken (see figure 3 below).

For COMM121 students, the highest marks were obtained by students attending a combination of $\mathrm{PO}$ and F2F sessions $(m=75.60)$, followed by F2F only $(m=69.78)$ and then Online only $(m=67.67)$. Conversely, students of NMIH106 gained higher marks when attending Online only versions of PASS $(m=74.22)$ or a combination of PO and F2F $(m=73.67)$, the lowest marks were achieved by students who attended F2F sessions only $(m=68.72)$. PSYC123 students performed almost equally across all three delivery modes of PASS: PO $(\mathrm{m}=73.00)$; $\mathrm{F} 2 \mathrm{~F}(\mathrm{~m}=73.26)$; and $\mathrm{PO}+\mathrm{F} 2 \mathrm{~F}(\mathrm{~m}=72.82)$. Whilst these differences were not statistically significant, it is interesting to note that students in different subjects gained varied benefits from the different PASS delivery modes.

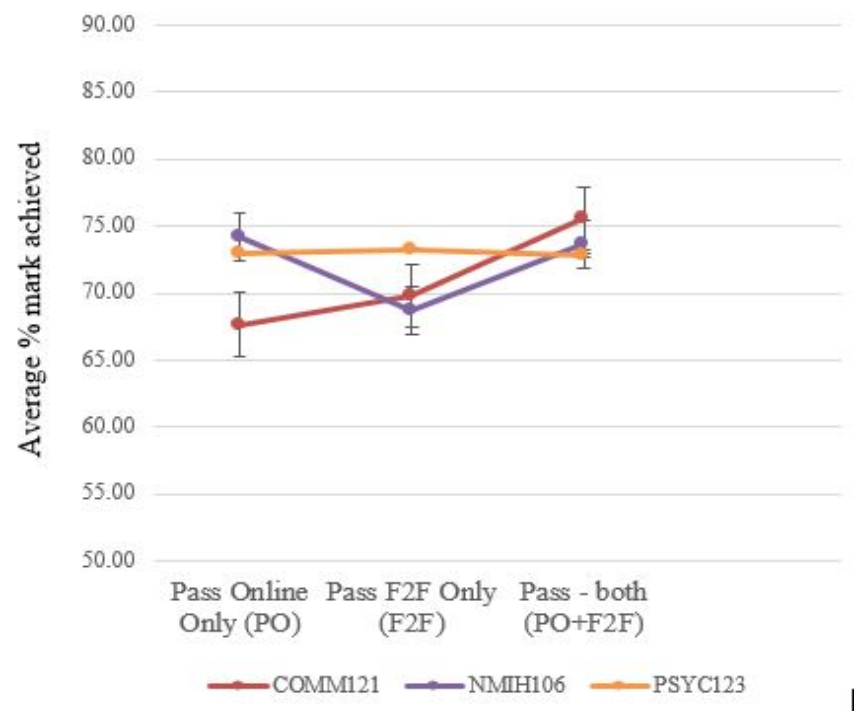

Figure 3: Comparisons of final average mark by subject and PASS delivery mode.

\subsection{Correlations}

To investigate the impact of hours of PASS, in its various modes, on final grade outcomes a series of correlations were conducted. Not surprisingly, there was a moderate positive, statistically significant result for number of PASS hours completed and final average marks via Pearson's Correlation Coefficient, $(\mathrm{r}(=.226, \mathrm{n}=409, \mathrm{p}<.001)$. Therefore, regardless of PASS delivery 


\section{T. Woolrych et al. / Advances in Science, Technology and Engineering Systems Journal Vol. 5, No. 1, 142-150 (2020)}

mode, the more hours completed by students, the higher their final mark.

This positive relationship held true for both NMIH106 $(\mathrm{r}=.25$, $\mathrm{n}=-119, \mathrm{p}=.006)$ and PSYC123 $(\mathrm{r}=.25, \mathrm{n}=169, \mathrm{p}=.001)$. For COMM121 however the relationship was not significant $(\mathrm{r}=.16$, $\mathrm{n}=121, \mathrm{p}=.079$ ). Looking into these correlations further, only positive relationships between hours and final marks were found for the F2F mode of PASS for NMIH106 ( $r=.28, \mathrm{n}=104$, p.004) and PSYC123 $(\mathrm{r}=.38, \mathrm{n}=137, \mathrm{p}<.001)$. All online modes returned non-significant results suggesting that for online versions students did not benefit from longer hours in PASS. The lack of student numbers in some of the online cohorts in this study, however, may have contributed to the non-significant results.

There were some negative relationships found, although they were non-significant. For COMM121 and PSYC123 students, hours spent in the PO+F2F mode of PASS was negatively correlated with final mark achieved, meaning that more hours did not necessarily equate to higher marks.

\section{Discussion}

Increasingly, institutions are offering online versions of programs to meet student demand for flexibility. Peer-led learning models have been found to benefit students in terms of final marks [5-6,22] as well as confidence [3]. However, whether these benefits can be successfully transferred to online versions is less clear. As Wang et al., [12] point out, online formats may not be able to replicate the stimuli and cues that are essential to interpersonal interactions and collaboration that can be found in F2F versions. Inconsistent results in the literature suggest this is a complex question [8] meaning other factors might be of influence. The findings from this Online PASS pilot highlight the fact that, depending upon the mode of PASS engaged in, student benefits in terms of final grades can vary. Students characteristics, which may help explain this variation, were not investigated in this current study, and should be the focus of future research.

Overall, students who attended PASS achieved significantly higher final marks compared to students who did not attend. This result seems to be driven by the F2F version of PASS, although there were no significant differences in final marks between PASS delivery modes. This is in line with previous literature that has highlighted the benefits of Peer-led learning programs [3, 24-26]. Therefore, PASS can result in positive benefits for students across a range of subjects, for the F2F version at least.

The results varied according to subject. For NMIH106 and PSYC123 there were benefits for students in the online versions of PASS, however COMM121 students seemed to struggle with this. In COMM121 in particular, numbers in the online cohorts were low which may have resulted in underpowering of the statistics used. This is not unusual according to the literature, where, despite student demand for more flexible learning options, when offered, the uptake is often low $[20,32,46]$.

This study also found that overwhelmingly students still prefer the F2F versions of PASS. Students straight from high school, and mature age students, may be less adept at learning in the online space, preferring the more familiar class-room-like environment. This may be due to a lack of confidence, knowledge and/or skills for online formats [3-4, 34-38]. Skills development is an important issue that should be addressed for students coming into University study. Enhancing students' online learning skills will help to build their confidence in the online space, making them better able to take advantage of PASS online.

The nursing subject, NMIH106, was the only subject where students in the online only condition achieved higher marks than students in the F2F only condition. Again, this highlights the fact that different subjects are host to students of varying characteristics that can impact the level of success they achieve in online learning formats. This finding is counter to much of the literature which indicate either F2F modes result in higher grades, or that there is no difference with the online version. Although the current results were not statistically significant, it was the only trend where average final marks were higher for the online versions compared to F2F. This may be reflective of a cohort effect. Nursing students in Australia tend to be older than most other first year university students [48] with a mean age of 28.6. Salamonson et al., [48] also reported that this cohort work an average of 13.6 hours a week, although it is unclear if this is above or below the average for other first year university students. Although age and work hours were not elicited in this study it may be reasonable to suggest that the UOW Nursing cohort are not unlike that of the Salamonson et al.'s study [48]. The fact that this group performed better in the online versions of PASS perhaps speaks to more mature timemanagement and self-motivation skills. The availability of an online peer assisted learning option may also be particularly helpful in overcoming barriers to scheduling F2F PASS in conjunction with compulsory practical placements for this cohort and their peer leaders. These factors should be investigated further.

Interestingly, the outcomes for both COMM121 and PSYC123 were quite different, despite both being first year statistics subjects. This suggests that different student cohorts may bring with them a different set of characteristics which may influence the success of online learning. Some students may be more prepared and have better time-management and self-motivation skills that are essential for this type of learning [3-4, 34-38]. More studies comparing subject cohorts across years should be conducted in order to clarify if the effect is due to characteristics as a result of subject/degree selection or a yearly cohort effect.

The hours spent at PASS was, in most cases, positively related to final marks, which is consistent with previous research [44]. However, for both COMM121 and PSYC123 students in the $\mathrm{PO}+\mathrm{F} 2 \mathrm{~F}$ condition a negative relationship between hours and final marks was found, although it was non-significant. Low participant numbers in the online conditions again may have contributed to the non-significant result, however it is an interesting trend. The negative relationship is difficult to explain except to say that other factors may be involved that were not the subject of this study. Both COMM121 and PSYC123 are statistics subjects, meaning students who attended both F2F and online PASS may have lacked confidence with the subject. It may also be the case that these students lacked the necessary skills to succeed, despite their PASS attendance. The role of PASS alongside other learning supports should be investigated further.

Self-selection bias is a common problem in peer-led learning program research, as it is often the most diligent students that 


\section{T. Woolrych et al. / Advances in Science, Technology and Engineering Systems Journal Vol. 5, No. 1, 142-150 (2020)}

attend [see 7, 49-50]. Students may participate in PASS for a number of reasons, including the drive to gain higher marks, or lack of confidence in the subject. Fetner [4] made the observation that some students struggle with the self-driven nature that is often inherent in the online learning space. Despite the flexibility this mode of learning affords students, a lack of time-management and self-motivation means those students may not be maximising the benefits that are on offer. This is particularly relevant for first year university cohorts who have not yet found the most efficient and effective study methods [43]. It has also been reported that students may push-back against online learning models, believing that the responsibility for their learning lies with the educators, rather than with themselves [14]. Therefore, it is imperative that students be offered the opportunity to develop the skills that will help them succeed in the online learning space.

Overall, the current study indicates that F2F versions of PASS deliver consistent benefits to students via increased grades, across a variety of subjects. The benefits to be had in the online learning modes, however, are less clear. The current study highlights the need to further investigate student and/or subject characteristics that may impact the benefits achieved by students engaging with the online format. Other factors such as student skills, maturity, and confidence, may be important factors that impact online learning outcomes. Similarly, subject characteristics should be studied which may reveal factors regarding the suitability of different subjects for this particular learning platform.

\subsection{Limitations}

Low student numbers in many of the online conditions may have undermined some of the inferential statistical analyses undertaken, therefore results should be interpreted with caution. Low sample sizes in online conditions is a problem in the literature $[20,32,46]$, where student uptake has been lacking. This problem can be overcome in the future through higher sample numbers, however, given that enrolment into online conditions is voluntary it is likely that this will continue to be a problem for future research. There are positive outcomes from this study that suggest, with the right supports and skills development, students can gain equal benefit from online versions of PASS as those obtained in F2F versions.

The high number of students who attended only 1 PASS may also have clouded results, underpowering the analysis, particularly for the correlations. Whilst some studies do not include students that have attended only 1 PASS class [7], it was decided that any student that attended any mode of PASS for at least one session be included in order to reduce the impact of low numbers in some of the online conditions.

It should also be noted that this was a Pilot study. Students at UOW had not previously had the opportunity to participate in PASS in the online format. Despite receiving specific training for the online space, PASS leaders themselves were learning along the way. Sessions at the beginning of the academic period may have been subject to technical issues, particularly in the statistics subjects where difficulty in sharing formulas and the creation of specific mathematical symbols was problematic. Therefore, the focus, in these early sessions, may have veered away from PASS activities and interactions to the implementation issues and student user troubleshooting. PASS leaders reported anecdotally that they, and their students, grew in confidence in working with the online system as the semester progressed. These lessons have now been included in the training guides and manuals for future PASS online leaders.

\section{Conclusion}

This study may explain some of the inconsistencies in findings for the Peer-led online learning space. Students from different subjects had differing outcomes dependent upon the type of PASS undertaken. This suggests that there may be underlying student characteristics which vary according to the subject taken, which may impact successful learning in the online space. Larger sample sizes, particularly for the online conditions, will help to clarify this, as will studies comparing results for the same subjects across years. Student characteristics such as work and/or family commitments, age, and other factors should also be investigated.

Students may also lack the necessary skills to succeed, particularly in the dimensions of self-motivation and timemanagement. Despite students reporting the online system easy to use, most students still showed a preference for the F2F format. This highlights the need for student skills development in the firstyear space so that students can more confidently and effectively take advantage of the flexible learning that PASS online can offer.

PASS can help students achieve higher marks. Overwhelmingly students that attended PASS F2F sessions achieved significantly higher marks compared to those who did not attend. There were a high number of students that attended only 1 session of PASS and it is unclear why this might be the case. What is clear is that dedication to PASS, in the form of multiple sessions, has benefits for students.

The study provides a useful contribution to the understanding of PASS style learning environments in the online mode. Consideration of subject selection, student demographics, technology available, training of peer leaders, and digital literacy of participants are areas for further investigation. Future studies should also investigate student and subject characteristics that may impact the benefits students gain from PASS. This study, limitations considered, indicates that not all subjects may be suitable for an online PASS platform. The role of peer assisted learning in online synchronous modes and how this relates to asynchronous interactions is outside the scope of this study, however, is an area for further investigation.

Peer-led learning programs are essential in helping students transition into university study. This PASS pilot demonstrates that, for traditionally difficult first year subjects, PASS can give students the winning edge they need. In this student-driven environment, students learn not only from PASS leaders, but from other students, engaging in discussions and activities that help elucidate the more difficult concepts in a subject, and also develop the study skills necessary to succeed. Venturing into the online space for Peer-led programs comes with it challenges, however with future studies investigating student characteristics and other factors that impact online learning outcomes will help ensure the future success of PASS Online.

\section{References}

[1] Gillies, D. "Student perspectives on videoconferencing in teacher education at a distance" Distance Education, 29(1), 107-118, 2008. 


\section{T. Woolrych et al. / Advances in Science, Technology and Engineering Systems Journal Vol. 5, No. 1, 142-150 (2020)}

[2] Kearsley, G. "Is online learning for everybody?" Educational Technology, 42(1), 41-44, 2002. Retrieved from http://www.jstor.org/stable/

[3] McKenzie, K., \& Schweitzer, R. "Who succeeds at university? Factors predicting academic performance in first year Australian university students" Higher Education Research \& Development, 20(1), 21-33, 2001.

[4] Fetner, M. "What do unsuccessful online students want us to know?" Journal of Asynchronous Learning Networks, 17(1), 13-27, 2013.

[5] Pereira, R. "UniPASS Report Semester 1 2012," Curtin University: Australia,2012. https://life.curtin.edu.au/local/docs/2012_S1_UniPASS Report Web Edit.pdf

[6] Taylor, $\bar{K}$., \& Kelly, T. "Comparison of effectiveness of several peer learning programs to support 1st year chemistry" in the 2014 Australian Conference on Science and Mathematics Education, 89-90, September 2014. (formerly UniServe Science Conference).

[7] Dawson, P., van der Meer, J., Skalicky, J. \& Cowley, K. "On the effectiveness of Supplemental Instruction: A systematic review of Supplemental Instruction and Peer-Assisted Study Session Literature between 2001 and 2010" Review of Educational Research, 84(4), 609-639, 2014.

[8] Yu-Chen, K., Hui-Chun, C., \& Chi-Hao, H. "A learning style-based grouping collaborative learning approach to improve EFL students' performance in English courses" Journal of Educational Technology \& Society, 18(2), 284-298, 2015

[9] Brandon, D., \& Hollingshead, A. "Collaborative learning and computersupported groups" Communication Education, 48(2), 109-126, 1999.

[10] Spaniol- Mathews, P., Letourneau, L.E., \& Rice, E. "The impact of online supplemental instruction on academic performance and persistence in Undergraduate STEM courses" Supplemental Instruction Journal, 2(1), 1932,2016

[11] Smith, J., Wilson, S. B., Banks, J., Zhu, L., \& Varma-Nelson, P. "Replicating Peer-Led Team Learning in cyberspace: Research, opportunities, and challenges" Journal of Research in Science Teaching, 51(6), 714-740, 2014.

[12] Wang, Q., Huang, C., \& Quek, C.L. 'Students' perspectives on the design and implementation of a blended synchronous learning environment" Australian Journal of Educational Technology, 34(1), 1-13, 2018

[13] Beaumont, T.J., Mannion, A.P., \& Shen, B.O. "From the campus to the cloud: The online Peer Assisted Learning Scheme" Journal of Peer Learning, 5(1), 1-15, 2012. http://ro.uow.edu.au/ajpl/vol5/iss1/6

[14] O'Flaherty, J., \& Phillips, C. "The use of flipped classrooms in higher education: A scoping review" Internet and Higher Education, 25, 85-95, 2015.

[15] Huijser, H., \& Kimmins, L. "PALS online and community building: A contradiction in terms?" in the ASCILITE 2005: 22nd Annual Conference of the Australasian Society for Computers in Learning in Tertiary Education: Balance, Fidelity, Mobility-Maintaining the Momentum? (1). Queensland University of Technology, Teaching and Learning Support Services, 2005.

[16] Larkin, H,.., \& Hitch, D. "Peer Assisted Study Sessions (PASS) preparing occupational therapy undergraduates for practice education: A novel application of a proven educational intervention" Australian Occupational Therapy Journal, 55, 100-109, 2019. doi: 10.1111/1440-1630.12537

[17] Topping, K. J. "The effectiveness of peer tutoring in further and higher education: A typology and review of the literature," Higher Education, 32(3), 321-345, 1996.

[18] Longfellow, E., May, S., Burke, L., \& Marks-Maran, D. “'They had a way of helping that actually helped': a case study of a peer-assisted learning scheme" Teaching in Higher Education, 13(1), 93-105, 2008. doi: $10.1080 / 13562510701794118$

[19] Capstick, S., \& Fleming, H. "Peer Assisted Learning in an Undergraduate Hospitality Course: Second Year Students Supporting First Year Students in Group Learning." Journal of Hospitality, Leisure, Sport and Tourism Education 1(1), 69-75, 2002.

[20] Brown, K., Nairn, K., van der Meer, J., \& Scott, C. "'We were told we're not teachers....it gets difficult to draw the line': Negotiating roles in PeerAssisted Study Sessions (PASS)" Mentoring \& Tutoring: Partnership in Learning, 22(2), 146-161, doi: 10.1080/13611267.2014.902559

[21] Cusick, A., Camer, D., Stamenkovic, A., \& Zaccagnini, M. "Peer Assisted Study Sessions for research trainees" Journal of Peer Learning, 8(14), 18-33, 2015. https://ro.uow.edu.au/ajpl/vol8/iss1/4

[22] Dancer, D., Morrison, K., \& Tarr, G. "Measuring the effects of peer learning on students' academic achievement in first-year business statistics" Studies in Higher Education, 40(10), 1808-1828, 2015.

[23] Lim, C., Anderson, F., \& Mortimer, R. "PASSport to the Cloud- Results of a Peer-Assisted Study Sessions (PASS) Online Pilot Program" Student Success, 7(2), 59-64, 2016.

[24] Carter-Hanson, C., \& Gadbury-Amyot, C. "Implementing Supplemental Instruction online to create success in high-stakes coursework for pre- doctoral dental students" Supplemental Instruction Journal, 2(1), 53-75, 2016

[25] Court, S., \& Molesworth, M. "Course-specific learning in peer assisted learning schemes: A case study of creative media production courses" Research in Post-compulsory Education, 13, 123-134, 2008.

[26] Evans, M.J., \& Moore, J.S. "Peet tutoring with the aid of the internet" British Jouranl of Educational Technology, 44(1), 144-155, 2013. doi:10.1111/j.1467-8535.2011.01280.x

[27] Finlay, K., \& Mitchell, M. Z. "Evaluating the effectiveness of online vs. face-to-face Supplemental Instruction in introductory biology courses" unpublished, University of Regina, 2017.

[28] Hizer, S. E., Schultz, P., W \& Bray, R. "Supplemental Instruction Online: As Effective as the Traditional Face-to-face model?" Journal of Science, Education \& Technology, 26(1), 100-115, 2017

[29] Bone, J., \& Edwards, S. "Connecting in rhizomic spaces: Peer-assisted learning (PAL) and e-learning in teacher education" Australian Journal of Adult Learning, 55(1), 54-74, 2015.

[30] Edwards, S., \& Bone, J. "Integrating peer assisted learning and eLearning: Using innovative pedagogies to support learning and teaching in higher education settings" Australian Journal of Teacher Education, 37(5), 1-12, 2012.

[31] Dekhinet, R., Topping, K., Duran, D., \& Blanch, S. "Let me learn with my peers online! Foreign language learning through reciprocal peer teaching" Innovate: Journal of Online Education, 4(3), 2, 2008.

[32] Watts, H., Malliris, M., \& Billingham, O. "Online Peer Assisted Learning: Reporting on practice" Journal of Peer Learning, 8(8), 85-104, 2015.

[33] Rourke, L., \& Anderson, T. "Using peer teams to lead online discussions" Journal of Interactive Media in Education, 2002, ART.1, 2002.

[34] McPherson, M., \& Nunes, M.B. "The failure of a virtual social space (VSS) designed to create a learning commuinity: Lessons learned" British Journal of Educational Technology, 35, 305-321, 2004.

[35] Lew, M.D.N., Alwis, W.A.M., \& Schmidt, H.G. “Accuracy of students' selfassessment and their beliefs about its utility" Assessment \& Evaluation in Higher Education, 35(2), 135-156, 2010. doi: 10.1080/02602930802687737

[36] Brouwer, J., Jansen, E., Hofman, A., \& Flache, A. "Early tracking or finally leaving? Determinants of early study success in first-year university students" Research in Post-Compulsory Education, 21(4), 376-393, 2016. doi: 10.1080/13596748.2016.1226584

[37] MacCaskill, A., \& Denovan, A. "Developing autonomous learning in first year university students using perspectives from positive psychology" Studies in Higher Education, 38(1), 124-142, 2013. doi:10.1080/03075079.2011.566325

[38] Mason, H.D. "Grit and academic perofrmance among first-year university students: A brief report" Journal of Psychology in Africa, 28(1), 66-68, 2018. doi:10.1080/14330237.2017.1409478

[39] Hryciw, D.H., Tangalakis, K., Supple, B., \& Best, G. "Evaluation of a peer mentoring program for a mature cohort of first-year undergaduate paramedic students" Adv Physiol Educ, 37, 80-84, 2013 , doi:10.1152/advan.00129.2012

[40] Cullity, M. "Challenges in understanding and assisting mature-age students who participate in alternative entry programs" Australian Journal of Adult Learning, 46(2), 175-201, 2006

[41] Spedding, J., Hawkes, A.J., \& Burgess, M. "Peer Assisted Study Sessions and student performance: The role of academic engagement, student identity, and statistics self-efficacy" Psychology Learning \& Teaching, 16(1), 144163, 2017. doi: $10.1177 / 1475725716687166$

[42] Seiber, V. "Diagnostic online assessment of basic IT skills in $1^{\text {st }}$-year undergraduates in the Medical Sciences Division, University of Oxford" British Journal of Educational Technology, 40(2), 215-226, 2009. doi:10.1111/j.1467-8535.2008.00926.x

[43] Smart, K.L., \& Cappel, J.J. 'Students' perceptions of online learning: A comparative study" Journal of Information Technology Education, 5, 201219, 2006.

[44] Ng, R., Kaur, A., Sheikh Mohamed, S. F., Latif, L. A., \& Bahroom, R. "Emathematics: pre-instructional and supplement instruction and their impact of student's online participation and final exam score" Asian Association of Open Universities Journal, 4(1), 27-36, 2009.

[45] Dennis, J. K. "Problem-based learning in online vs. face-to-face environments" Education for Health, 16(2), 198-209, 2003.

[46] Zaccagnini, M., \& Verenikina, I. "Peer assisted study sessions for postgraduate international students in Australia" Journal of Peer Learning, 6, 86-102, 2013.http://ro.uow.edu.au/ajpl/vol6/iss1/8

[47] Nikolic, S. \& Nicholls, B. "Exploring Student Interest of Online Peer Assisted Learning Using Mixed-Reality Technology" Advances in Intelligent Systems and Computing, 715, 48-54, 2017. 
[48] Salamonson, Y., Ramjan, L., Lombrado, L., Lanswer, L.D., Fernandez, R., \& Griffiths, R. "Diversity and demographic heterogeneity of Australian nursing students: a closer look" International Nursing Review, 59(1), 59-65, 2011.

[49] Kochenour, E.OD.S., Jolley, J.G., Kaup, D.L., Roach, P.K.D., \& Wenzler, L.A. "Supplemental Instruction: An effective component of student affairs programming” Journal of College Student Development, 38(6), 577-586, 1997.

[50] MCarthy, J. "Blended learning environments: Using social networking sites to enhance the first year epxerience" Australiasian Journal of Educational Technology, 26(6), 729-740, 2010. 